Amines and quaternary ammonium compounds have not yet been appliod so oxtensively as organo-phosphorus compounds, but the five reviews devoted to them suggested they will be found increasingly useful for the extraction of acids and for the separation of the platinum group metals and of the transuranium elements. Other papers surveyed developments in the application of solvent extraction to analytical purposes and to the extraction of fission products from the waste liquors that occur from the troatment of irradiated fuels.

The final session was of particular interest to those concerned with the operation of tributyl phosphate processes for the separation of fissile material from irradiated reactor fuels. The papers and the discussion which followed dealt with chemical aspects of the degradation (by thermal and radiolytic reactions) of tributyl phosphate itself and of the hydrocarbon diluent which form the bulk of the organic phase. Complementary studies at the Atomic Energy Research Establishment, Harwell, and at Windscale Technical Works have identified the class of compounds responsible for the retention of fission product zirconium in the organic solvent aftor it has been in use for several months; the compounds are certain hydroxarnic acids, present at less than $10^{-5} \mathrm{M}$ and dorivod from the nitration of the diluent.

The symposium was organized by a committeo under K. B. Brown as chairman. The papers are to be published in Nuclear Science and Engineering. J. M. FLETCHER

\title{
HYDRAULICS AND FLUID MECHANICS
}

A CONFERENCE on "Hydraulics and Fluid Mechanics" was held at the University of Western Australia, Nedlands, during December 6-13. It was sponsored by the Faculty of Engineering and is to be the forerunner of a triennial series. These will be held initially in Australia or New Zealand and will be known as Australasian Conferences on Hydraulics and Fluid Mechanics.

The inclusion of both the terms was for the purpose of attracting a wide variety of papers. This aim was fulfilled and the conference assisted in bringing applied mathematicians, physicists and engineөrs closer together in a most co-operative atmosphere. It also helped to make the attendance sufficient for all activities associated with such conferences to be undertaken. This is a particular problem presented to conference conveners in Australia and New Zealand, where travel distances are so great and specialists in any field so few. In these circumstances, most attenders must bo authors to warrant travel subsidy by an employer, and a wide variety of topies must be accepted so that the gathering warrants the outlay to attend.

The open invitation resulted in 57 papers being presented or tabled during the course of the five working days. In each session of one and a half hours three papers were generally presented. Each author had twenty minutes for presentation, which left half an hour for discussion of all papers. Some concurrent sessions were necessary.

The proceedings of the conference are to be published by Pergamon Press and should be available about May 1963. The volume will contain approximately half the papers submitted, together with the inaugural address delivered by Prof. Hunter Rouse, director of the Iowa Institute of Hydraulics Research. It was appropriate that Prof. Rouse should be guest at this first conference of a new series having been inaugurator of the renowned series of Iowa Hydraulics Conferences.

Reference was made to the Iowa series and the different approach mado in it and the present conference. For example, the former had specific themes with solicited spoakers while the latter covered a wide range of topics with unsolicited papers. Prof. Rouse rocommended experimentation in the various facets of organizing the conforence. As future gatherings are to be the sole responsibility of the university which chooses to hold it, such variations are likely. The only probable common denominators are the neөd for a wide variety of papers, for the reasons given here, and the desirability of having as many overseas visitors as possible.

Prof. Rouse's address was entitled "On the Art of Advancing the Science of Hydraulics", emphasis being placed on 'scionco' as distinct from applications, and 'hydraulics' which connoted a specific branch of fluid mechanics-the sturdy offspring which the original empirical experimentation of hydraulics begot. Speaking on the part played by the university, Prof. Rouse sub- mittod that fundamental rosoarch was as essential to it as was higher oducation. He accepted that product or process development had its creative or instructive sides, but that routine testing, involving no new proceduros or concepts, should be reserved for the commercial laboratory or the technical institute. Other requirements in the art of advancing any field of knowledge were froo oxchange of ideas among research workers and emphasis on good staff above all else-equipment, buildings, maintenance, funds, etc.

The conference papers of more direct interest to engineers have boen summarized elsewhere ${ }^{1,2}$ and hence only those of general scientific interest will be included here. The topies on which two or more papors wore received included flow through porous media, the effect of vortices, waves and guided weapon research.

\section{Porous Media}

R. A. Wooding (Appliod Mathematies Laboratory of the Departmont of Scientific and Industrial Research, Wellington, New Zealand) presented a paper entitled "Mixing Layers in Flow Through Porous Media". It treated properties of steady vertical convection from a sourco of heat, or of heated fluid in a saturated porous medium, when the Rayleigh or Péclet number was vory large. The effects of thermal diffusion were important only in zones of mixing between fluids at different temperatures. Flows of this type could be expocted in geothermal regions.

J. de Yong (Commonwealth Scientific and Industrial Research Organization, Division of Forest Products, Melbourne) discussed the morits of applying capillary or drag models to flow through media of high porosity. The paper was aimed specifically at paper pulp pads, and emphasized consideration of rheological properties in evaluating permeability. Various theories were described and tests reported, from which it was concluded that the 'drag equations' described the permeability flow-rate relationship most accurately.

\section{Vortices}

A paper entitled "Sink Vortices and Whirlwinds" was presented by E. K. Wobb (Commonwealth Scientific and Industrial Research Organization, Meteorological Physics Division, Melbourne). Whirlwinds develop only over smooth ground when thore is strong thermal convection (ground hotter than air) with a light wind. The criterion for tho formation of a whirlwind was developed in terms of inflow and an effectivo turbulent viscosity. It was only when a significant portion of the inflow shrank into the molecular conduction boundary layer that this criterion was satisfied. The equation was derived which satisfied this latter condition. It corrosponded to a wind 
less than one metre per second over bare ground on a summer's day.

E. Inoue (Division of Meteorology, National Institute of Agricultural Sciences, Tokyo) discussed the "Horizontal Diffusion over the Sea Surface". He applied the techniques of analysing the diffusing smoke puffs and plumes in the atmosphere to similar phenomena in the soa. In this way oceanic turbulence can be gauged. Two types of diffusion were considered; that generated instantaneously and that from a fixed source over time. Equations were presented for the variation of area with time and the vanishing time of the dye patch. These results are applicable to problems of sea pollution, such as ship discharge, sewage outfalls and the marine disposal of radioactive wastes.

A paper from the University of New South Wales, Sydney, entitled, "The Motion of a Two-Dimensional Buoyant Vortex" was presented by I. R. Wood. The theory of the vortex pair was modified to include the offect of walls and for the case of sloping walls the component of the buoyant force. Tests were conducted in a 'Perspex' flume with coloured dyo identifying a vortox of salt solution entering a fresh-water medium.

\section{Waves}

The paper "An Exact Theory of Simple, Finite Shallow Water Oscillations on a Rotating Earth" approached the problem from the unusual angle of taking a simple form of liquid motion and finding the shape of basin necessary to produce it. The author, F. K. Ball (Commonwealth Scientific and Industrial Rosearch Organization, Metoorological Physics Division, Melbourno), discussed two simple types of motion: "pure displacement" and "pure distension". The former is a lateral displacement without change in depth profile and was found to oceur only in a paraboloid. The latter consists of a combination of a uniform, two-dimonsional isotropic dilation and a rotation, and could only occur in a paraboloid of revolution if the underlying surface were axially symmetric. The governing equations in both cases were simple linear differontials with constant coefficients.

J. W. Miles (Australian National University, Canberra) presented a roviow paper on the generation of surface waves by shear flows, especially with regard to wind blowing over water. Theories were cited which involved the direct action of turbulent fluctuations in pressure on the water surface and those concorned with an instability mechanism whoreby energy was transferred from shear flow to the surface wave. Observational evidence by Longuet-Higgins ${ }^{3}$ was diseussed from which it was shown that energy transfer to ocean waves was probably produced through the instability mechanism. Other topics pertaining to transfer of energy wero presented.

H. C. Lovey (Univorsity of Western Australia, Perth) presented a paper entitled "Diffraction in Fluid Mochanics". The acoustic equations that are used to discuss the propagation of small disturbances in a gas aro only approximations. They govern, in fact, the first-order terms that arise from an assumed regular perturbation expansion in the maximal disturbanco strength. It was shown that in pulse diffraction problems the acoustic approximation always leads to a singularity of a kind unacceptable in gas dynamies in the shadow boundary. It was submitted, therefore, that although such problems were of a singular perturbation type they required different techniques from those usually applicable in wave propaga. tion problems.

\section{Guided Weapons Research}

Two papers were submitted on this topic from the Weapons Research Establishment at Salisbury, South Australia.

The first, by H. C. Newbigin, was concerned with aorodynamic data obtained from a wind tunnel from which a comprehensive mathematical model was derived. This model was later correctod with the aid of flight trial data, which could not be adequately analysed until a high-spoed computer became available. It was found that important aorodynamic derivatives obtained from the wind-tunnel tests were incorroct. Although these could be readily adjusted from the prototype tests, the roason for the discrepancy had not yet been found.

The second paper, submitted by B. Goodwin, roforred to the mathematical modelling of the fuel system of a guided weapon. The fuel flow to the engines of a missile determines its effective range, it must therefore be known to a high degree of accuracy. In ono weapon under consideration the fuel flow was a function of the Mach numbor and ambient conditions. A control system with a number of feed-back loops controlled this flow, and was devised from a comprehensive mathematical model basod on an examination of the various physical components.

\section{R. Silvester}

2 Water Power (London, in the press).

${ }_{2}^{2} J$. Inst. Eng. A ustral. (in the press).

${ }^{3}$ Longuet-Higgins, M. S., Proc. Roy. Soc., A, 265, 286 (1962).

\section{THE NATIONAL RESEARCH DEVELOPMENT CORPORATION}

$\mathrm{T}$ HE annual report and statement of accounts of the National Research Development Corporation for the year ended June $30,1962 *$, surveying the thirteenth year of the Corporation's activities, discusses at somo length, in view of the attention which is at present being given in Government support of civil development work in industry, the extent to which the Corporation is achieving its purposes and the main disabilities under which it has to operate. For the rest, the report stresses the progress made in furthering the hovereraft project; four prototypes of the second generation are undergoing trials, including oxperimental operational use in ferrying passengers on selected routes. However, much development is still required before this new form of transport bocomes fully established commercially, and further development would be greatly advanced if commercial or other operators who

* National Research Development Corporation. Report and Statement of Accounts for the year 1st July, 1961, to 30th June, 1962. Pp. ii +34 (London: H.M.S.O., 1963.) 2s. 3d. net. (See also p. 929 of this issue of Nature.) have specific operational requirements which hovercraft can meet were to place orders now. In the Dracone project for flexiblo barges, development of the larger sizes is still proceeding and commorcial sales of the sizes already developed doubled, largely for export. A major advance is noted in the administrative arrangoments for the fuel cell project; further devolopment will be supported by a company formed for the purpose, Enorgy Conversion, Ltd. Commercial interest in cephalosporin $c$ has been fully maintained and the Corporation is evon more hopeful that this antibiotic, which is resistant to penicillinase, will play a useful part in medical therapy. Other major revenue-earning inventions listed includo the alignment of light projectors; anemometers; anti-carcinogenic compounds; anti-thyroid compounds; Bailoy bridge; collet chucks; electrically conductive films; electronic computers; exploders for firing charges electrically; fog detectors; glass fire and heat detectors; gyroscopic apparatus; hecogenin; ignition systems; ionization gas detectors; insecticidal fumer; manufacture of cheese; 